\title{
Expanded Hemodialysis and Its Effects on Hospitalizations and Medication Usage: A Cohort Study
}

\author{
Rafael M. Sanabria ${ }^{a}$ Colin A. Hutchison $^{b}$ Jasmin I. Vesga ${ }^{c}$ Juan G. Ariza ${ }^{d}$ \\ Ricardo Sanchez ${ }^{\mathrm{e}}$ Adriana M. Suarez ${ }^{\mathrm{C}}$ \\ aRenal Therapy Services-Latin America, Bogotá, Colombia; bepartment of Medicine, Hawke's Bay District Health \\ Board, Hastings, New Zealand; 'Renal Therapy Services-Colombia, Bogotá, Colombia; 'Baxter Latin America, Bogotá, \\ Colombia; 'Clinical Research Institute, School of Medicine, Universidad Nacional de Colombia, Bogotá, Colombia
}

\section{Keywords}

Colombia $\cdot$ Kidney failure $\cdot$ Hemodialysis - Expanded

hemodialysis · Hospitalization · Medium cut-off membranes

\begin{abstract}
Introduction: Expanded hemodialysis (HDx) effectively removes large middle molecular uremic toxins ( $>25 \mathrm{kDa}$ ) while still retaining albumin, potentially reducing their adverse effects. We compare the clinical laboratory parameters, hospitalization rates, and medication use in a cohort of patients switched from high-flux HD to HDx. Methods: This is a multicenter, observational cohort study of 81 adult patients, across 3 clinics, with end-stage kidney disease (ESKD) on chronic hemodialysis (HD). Patients received high-flux HD for at least 1 year and then switched to HDx and were followed up for 1 year. Patients were excluded if they discontinued therapy, changed provider, underwent kidney transplant, recovered kidney function, or changed to peritoneal dialysis, another dialyzer, or renal clinic. Results: Twelve months after switching to HDx, the rate of hospitalization events per patient-year decreased from 0.77 (95\% Cl: 0.60$0.98,61$ events) to 0.71 ( $95 \% \mathrm{Cl}: 0.55-0.92,57$ events) ( $p=$ $0.6987)$. The hospital day rate per patient-year was significantly reduced from 5.94 days in the year prior to switching
\end{abstract}

compared with 4.41 days after switching ( $p=0.0001)$. The mean dose of erythropoiesis-stimulating agent (SC epoetin-a) and intravenous iron also significantly decreased ( $p=0.0361$ and $p=0.0003$, respectively). Conclusion: Switching to HDx was associated with reductions in hospital day rate and medication use, suggesting HDx has the potential to reduce the burden of ESKD on patients and healthcare systems.

(C) 2021 The Author(s)

Published by S. Karger AG, Basel

\section{Introduction}

Worldwide, the number of patients with chronic kidney disease (CKD) [1] and end-stage kidney disease (ESKD) [2] is large and expanding. Recent years have seen improved patient outcomes [3] including reduced mortality rates [4], improved 5-year survival [5], and reduced morbidity $[6,7]$. However, ESKD continues to place a substantial burden on healthcare systems and patients worldwide. A contributing factor to this process is the retention of a group of large uremic toxins $(>25 \mathrm{kDa})$, now referred to as large middle molecules [8].

In a systematic review of the role of large middle molecules in ESKD, Wolley and Hutchison [8] identified karger@karger.com www.karger.com/nef

Karger $\stackrel{\text { ' }}{5}$

GOPEN ACCESS
(C) 2021 The Author(s)

Published by S. Karger AG, Basel

This is an Open Access article licensed under the Creative Commons Attribution-NonCommercial-4.0 International License (CC BY-NC) (http://www.karger.com/Services/OpenAccessLicense), applicable to the online version of the article only. Usage and distribution for commercial purposes requires written permission.
Rafael M. Sanabria

Renal Therapy Services LA

Transversal 23 \#97-73, 6th Floor

Bogota, D.C. 110221002 (Colombia)

mauricio_sanabria@baxter.com 
Fig. 1. Flowchart of the patients in the study: consort diagram showing the flow of patients in the study. Of the 175 patients originally recruited, 23 did not meet the eligibility criteria. Prior to switching, 48 patients were lost during the high-flux HD potion of the study and 23 were lost during the HDx portion, leaving 81 patients eligible for analysis. HF-HD, high-flux hemodialysis; HDx, expanded hemodialysis; PD, peritoneal dialysis.

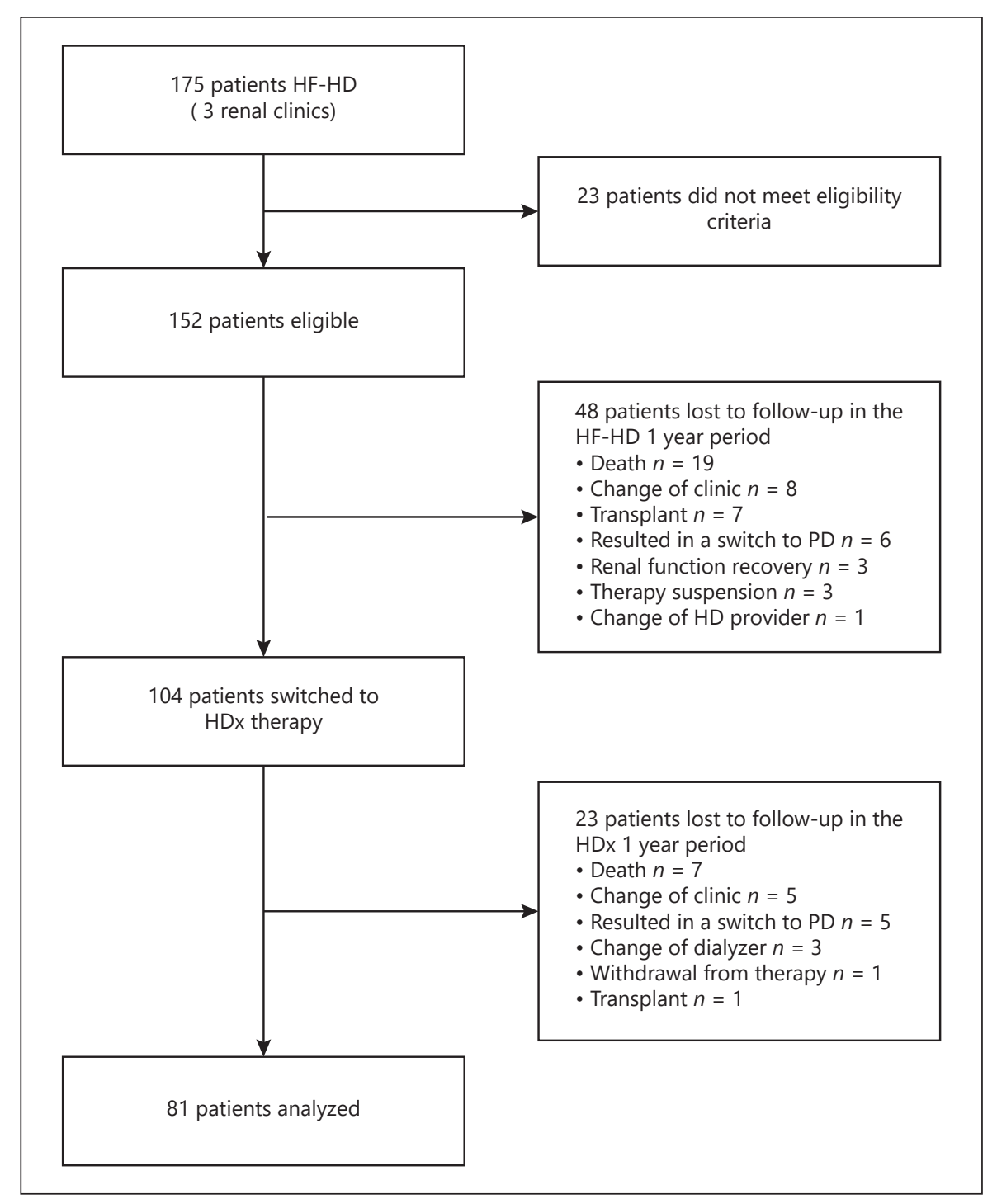

these historically difficult-to-remove-uremic toxins are involved in several key biological pathways which drive adverse outcomes. These include chronic inflammation, secondary immunodeficiency, atherosclerosis, left ventricular hypertrophy, and kidney anemia. Of these processes, chronic inflammation has been particularly well described for its role in adverse outcomes for patients with ESKD through mechanisms such as protein-energy wasting, decline in cognition, disturbed mineral metabolism, cardiovascular disease, and overall mortality $[9,10]$. The link between large middle molecules and secondary immunodeficiency largely results from the suppression of normal activation of neutrophils by these toxins. The impact of large middle molecules on cardiovascular outcomes, both left ventricular hypertrophy and atheroscle- rosis, results from approximately $50 \%$ of described large middle molecules affecting numerous biological pathways. Finally, kidney anemia and erythropoiesis-stimulating agent (ESA) resistance are in part linked to the poor clearance of hepcidin on conventional dialysis [11].

Historically, the removal of middle molecules during hemodialysis (HD) is in part limited by the properties of the membrane. Recently, a new medium cut-off (MCO) membrane has been developed which expands the capacity of HD to remove large middle molecules $(>25 \mathrm{kDa})$, without significant loss of albumin [12]. This new therapy is termed expanded hemodialysis (HDx), and in clinical trials, clearances of middle molecules during $\mathrm{HDx}$ exceeded the clearances provided by high-flux membranes in HD and HDF mode [13]. As studies have previously 


\begin{tabular}{|c|c|c|c|c|c|c|c|c|c|c|c|c|c|}
\hline \multirow{2}{*}{$\begin{array}{l}1 \text { year follow-up } \\
\text { measurement } \\
\text { variables in HF-HD } \\
\text { and year } \\
\text { follow-up } \\
\text { measurement } \\
\text { variables in HDx }\end{array}$} & \multirow[b]{2}{*}{ Baseline } & \multirow[b]{2}{*}{ Month } & \multirow[b]{2}{*}{ Month } & \multirow[b]{2}{*}{ Month } & \multirow[b]{2}{*}{ Month } & \multirow[b]{2}{*}{ Month } & \multirow[b]{2}{*}{ Month } & \multirow[b]{2}{*}{ Month } & \multirow[b]{2}{*}{ Month } & \multirow[b]{2}{*}{ Month } & \multirow[b]{2}{*}{ Month } & \multirow[b]{2}{*}{ Month } & \multirow[b]{2}{*}{ Month } \\
\hline & & & & & & & & & & & & & \\
\hline $\begin{array}{l}\mathrm{Hb} \text {, erithropoietin } \\
\text { resistance, } \mathrm{Kt} / \mathrm{V}\end{array}$ & $x$ & $x$ & $x$ & $x$ & $x$ & $x$ & $x$ & $x$ & $x$ & $x$ & $x$ & $x$ & $x$ \\
\hline $\begin{array}{l}\text { PTHi, TSAT, } \\
\text { ferritin, Fe }\end{array}$ & $x$ & & & $\mathrm{x}$ & & & $\mathrm{x}$ & & & $x$ & & & $x$ \\
\hline $\begin{array}{l}\text { ESA, iron, calcium } \\
\text { carbonate, } \\
\text { aluminium } \\
\text { hydroxide }\end{array}$ & $x$ & & & $\mathrm{x}$ & & & $x$ & & & & & & $x$ \\
\hline \multicolumn{14}{|l|}{$\begin{array}{l}\text { Hospitalization } \\
\text { events, days } \\
\text { hospitalization and } \\
\text { readmission }\end{array}$} \\
\hline $\begin{array}{l}\text { Withdraw or end } \\
\text { of follow-up }\end{array}$ & & & & & & & & & & $\rightarrow$ & & & \\
\hline
\end{tabular}

Fig. 2. Schedule of visits during the high-flux HD and HDx portions of the study. ${ }^{*}$ Only for diabetic patients. CA, calcium; ESA, erythropoiesis-stimulating agent; Fe, iron; Hb, hemoglobin; HbAlc, glycated hemoglobin; HDx, expanded hemodialysis; HF-HD, high-flux hemodialysis; hsCRP, high-sensitivity C-reactive protein; Kt/V, dialysis dose; P, phosphate; PTHi, parathyroid hormone; TSAT, transferrin saturation.

demonstrated that increased clearance of large middle molecules can improve patient care and outcomes [14], there is now significant interest in the ability of HDx to improve patient outcomes through multiple pathways, such as inflammation [15].

While there are several international studies starting to explore potential patient benefits of $\mathrm{HDx}$ in prospective studies, the introduction of HDx to Colombia in 2017 has provided the ability to report real-life comparative data of the effects of HDx on outcomes of interest. In this article, we report the key clinical parameters, hospitalization rates, and medication use before and after transition from high-flux HD to HDx in a stable cohort of chronic dialysis patients.

\section{Materials and Methods}

\section{Study Design and Patients}

This historical, multicenter, observational cohort study of chronic HD patients was undertaken in 3 Renal Therapy Services clinics in Bogotá, Colombia. Inclusion criteria consisted of the following: 18 years of age or greater, established ESRD treated with chronic HD, patients had to have received high-flux HD for at least 1 year prior to conversion to HDx and then maintained on $\mathrm{HDx}$ for at least 1 year.

Dialysis clinic inclusion was based on standardized process and electronic medical record, and only centers where $100 \%$ of patients switched from HD to HDx were included. Patients were required to receive both treatments at the same center. Patients were excluded if they discontinued therapy, changed dialysis provider, had a kidney transplant, recovered kidney function, or switched to peritoneal dialysis, another hemodialyzer, or renal clinic (Fig. 1).

All patients provided written informed consent, and the study was conducted in accordance with the principles of the Helsinki Declaration and Good Clinical Practices. The study protocol was approved by the clinical research ethics committee of Renal Therapy Services (RTS), December 11, 2018, Minute, Item No. 025.

\section{Hemodialysis Treatments Administered}

Hemodialysis treatments were administered by clinical staff at local RTS centers. Patients who had received high-flux HD (Polyflux 140; Revaclear 300 or 400, Baxter, Deerfield, IL, USA) thrice weekly for $4 \mathrm{~h}$, for at least 12 months, were switched to receive HDx (Theranova; Baxter, Deerfield, IL, USA). The patient's prescriptions $\left(Q_{\mathrm{D}}, Q_{\mathrm{B}}\right.$, target $\mathrm{Kt} / \mathrm{V}$, duration, and dialysate) were not changed as part of this study. An existing functioning permanent vascular access (AVF, AVG, or permanent $\mathrm{HD}$ catheter) was re- 
Table 1. Demographics of the study population at time of entry

\begin{tabular}{lc}
\hline Patient demographics & $N=81$ \\
\hline Age, years; mean (SD) & $61.1(12.6)$ \\
Male, $n$ (\%) & $52(64.2)$ \\
CKD cause, $n$ (\%) & \\
$\quad$ Diabetes mellitus & $32(39.5)$ \\
Hypertension & $23(28.4)$ \\
$\quad$ Obstructive & $5(6.2)$ \\
Glomerular/autoimmune & $3(3.7)$ \\
Unknown & $13(16.0)$ \\
$\quad$ Others & $5(6.2)$ \\
Vintage in RRT; median (IQR) & $3.8(9.4)$ \\
Influenza vaccine, $n$ (\%) & $68(84.0)$ \\
Pneumococcal vaccine, $n$ (\%) & $12(14.8)$ \\
Vascular access, $n$ (\%) & \\
$\quad$ Vascular catheter & $19(23.5)$ \\
Arteriovenous fistula & $62(76.5)$ \\
Time per HD session, h; mean (SD) & $4(0)$ \\
Dialysate flow rate, mL/min; mean (SD) & $500(0)$ \\
Blood flow rate, mL/min; mean (SD) & $391.5(50.2)$ \\
Ultrafiltration, L; mean (SD) & $2(0.7)$ \\
Dialyzer type in before phase, $n$ (\%) & \\
Polyflux 140 & $5(6.2)$ \\
Revaclear 300 & $60(74.1)$ \\
Revaclear 400 & $16(19.8)$ \\
Dialyzer type in after phase, $n$ (\%) & \\
Theranova 400 & $68(84.0)$ \\
Theranova 500 & $13(16.0)$ \\
Body mass index, kg/m ${ }^{2} ;$ mean (SD) & $25(4)$ \\
Systolic blood pressure, mm Hg; mean (SD) & $131(18)$ \\
Diastolic blood pressure, mm Hg; mean (SD) & \\
\hline
\end{tabular}

CKD, chronic kidney disease; RRT, renal replacement therapy; $\mathrm{HD}$, hemodialysis; SD, standard deviation; IQR, interquartile range; $\mathrm{mm} \mathrm{Hg}$, millimeters of mercury.

quired but the interim use of temporary dialysis catheters was permitted. Dialyzers were not reused. Regarding dialysate composition, all the patients used a standard solution containing the following: bicarbonate, $34 \mathrm{mEq} / \mathrm{L}$; potassium, $2 \mathrm{mEq} / \mathrm{L}$; chloride, $109.5 \mathrm{mEq} / \mathrm{L}$; calcium, $1.75 \mathrm{mEq} / \mathrm{L}$; magnesium, $0.5 \mathrm{mEq} / \mathrm{L}$; and acetic acid, $3.0 \mathrm{mEq} / \mathrm{L}$. Sodium conductivity was adjusted according to medical prescription.

\section{Patient Demographics and Clinical Characteristics}

Information on patient demographic characteristics including age, sex, cause of CKD, diabetes status, duration of dialysis, and influenza and pneumococcal vaccination status were collected. Treatment parameters including vascular access, HD session duration, dialysate flow rate, blood flow rate, and dialyzer type were also collected. The following laboratory parameters were collected: hemoglobin, albumin, phosphorus, platelet-lymphocyte ratio, ferritin, transferrin saturation, glycosylated hemoglobin, and singlepool Kt/V (spKt/V). Monthly data on medication prescriptions of ESA and IV iron were also extracted from the medical records.

\section{Outcomes}

Outcomes studied were laboratory parameters, annual hospitalization rates, hospitalization rates by causes, annual hospital stay, 30-day readmission rates, adverse events related to hemodialysis procedures, and medication use. All outcomes were assessed during the year on HF-HD and the year after switching to HDx. In instances of missing data, no data imputation was carried out, and for the specific case of albumin, an approach was made by intention to treat and by protocol. Methoxy polyethylene glycol-epoetin beta was converted to international units using the conversion factor of $4 \mu \mathrm{g}$ every 4 weeks for each weekly dose of 125 IU epoetin- $a$ [16]. The schedule of measurements is shown in Figure 2.

\section{Statistical Analysis}

A statistical description was prepared for all the variables, including calculations of the central trend measures and dispersion, quantitative variables, and determinations of absolute frequencies for qualitative variables. The Wilcoxon signed-rank test was used to evaluate any differences before and after switching to HDx to account for the distribution of continuous variables. Rates of hospitalization, hospital days, and hospital readmission were estimated where the numerator was constituted by the number of events and the denominator by the time contributed by each patient within the study. These rates were presented with their respective $95 \%$ confidence intervals. The incidence rates pre- and post-HDx were compared using the incidence rate ratio. The hospitalization event was counted if the duration was 1 day or more. A readmission event was counted when the new hospitalization occurred between the fourth and thirtieth day of hospital discharge immediately before. Stata Statistical Software: Release 14 (StataCorp LP, College Station, TX, USA) was used to perform statistical analyses. Two-tailed tests were used, and a $p$ value of $<0.05$ was considered significant.

\section{Results}

\section{Patient Demographics and Treatment Parameters}

Of a potential 175 patients receiving HF-HD at the 3 study clinics, a total of 81 patients were included in the analysis (Fig. 1). Twenty three did not meet eligibility criteria, 48 were lost to follow-up during the HF-HD period, and 23 were lost during the HDx study period, leaving 81 patients for analysis. Patient demographics are shown in Table 1. At baseline, the mean age of patients was 61.1 years (standard deviation [SD], 12.6) and 52 (64.2\%) were male. The most common cause of ESKD was diabetic kidney disease (32 patients, 39.5\%), followed by hypertension $(23,28.4 \%)$. Prior to switching to HDx, patients had been receiving HF-HD for a median of 3.8 (interquartile range [IQR] 9.37) years.

The majority of patients had an arteriovenous fistula (76.5\%) for vascular access (Table 1). Hemodialysis treatment parameters were a $Q_{D}$ of $500 \mathrm{~mL} / \mathrm{min}(\mathrm{SD} 0)$ and $Q_{B}$ of $391.48 \mathrm{~mL} / \mathrm{min}$ (SD 40.22) using standard high-flux dialyzers. 
Table 2. Laboratory results before and after switching to HDx

\begin{tabular}{|c|c|c|c|c|c|c|c|}
\hline Parameters & Mean & $\mathrm{SD}$ & $\mathrm{P}_{25}$ & Median & $\mathrm{P}_{75}$ & IQR & $p$ value* \\
\hline \multicolumn{8}{|l|}{ Anemia profile } \\
\hline \multicolumn{8}{|c|}{ Hemoglobin, g/dL } \\
\hline Before & 12.10 & 1.94 & 10.80 & 11.90 & 13.10 & 2.30 & \multirow[t]{2}{*}{0.397} \\
\hline After & 12.09 & 1.80 & 10.90 & 11.80 & 13.10 & 2.20 & \\
\hline \multicolumn{8}{|c|}{ Erythropoietin resistance } \\
\hline Before & 5.26 & 5.68 & 0.00 & 4.16 & 8.03 & 8.03 & \multirow[t]{2}{*}{0.016} \\
\hline After & 4.84 & 5.85 & 0.00 & 3.37 & 7.28 & 7.28 & \\
\hline \multicolumn{8}{|c|}{ Ferritin, ng/mL } \\
\hline Before & 745.96 & 724.96 & 194.10 & 482.70 & $1,129.00$ & 934.90 & \multirow[t]{2}{*}{0.855} \\
\hline After & 727.94 & 700.82 & 199.60 & 530.20 & $1,025.00$ & 825.40 & \\
\hline \multicolumn{8}{|l|}{ TSAT, $\%$} \\
\hline Before & 30.21 & 14.57 & 22.33 & 27.73 & 36.81 & 14.28 & \multirow[t]{2}{*}{0.454} \\
\hline After & 33.14 & 15.27 & 22.43 & 31.01 & 38.70 & 16.27 & \\
\hline \multicolumn{8}{|c|}{ CKD-bone mineral disease } \\
\hline \multicolumn{8}{|c|}{ Phosphorus, mg/dL } \\
\hline Before & 4.60 & 1.39 & 3.67 & 4.47 & 5.40 & 1.73 & \multirow[t]{2}{*}{0.004} \\
\hline After & 4.44 & 1.36 & 3.44 & 4.29 & 5.31 & 1.87 & \\
\hline \multicolumn{8}{|c|}{ Calcium, mg/dL } \\
\hline Before & 8.84 & 0.82 & 8.37 & 8.80 & 9.35 & 0.98 & \multirow[t]{2}{*}{0.188} \\
\hline After & 8.88 & 0.84 & 8.40 & 8.88 & 9.40 & 1.00 & \\
\hline \multicolumn{8}{|c|}{ PTHi, \% pg/mL } \\
\hline Before & 458.21 & 436.44 & 155.00 & 314.95 & 608.50 & 435.50 & \multirow[t]{2}{*}{0.003} \\
\hline After & 461.45 & 449.41 & 154.20 & 318.10 & 568.20 & 414.00 & \\
\hline \multicolumn{8}{|l|}{ Inflammation } \\
\hline \multicolumn{8}{|c|}{ Albumin, g/dL } \\
\hline Before & 3.99 & 0.35 & 3.80 & 4.01 & 4.23 & 0.43 & \multirow[t]{2}{*}{0.082} \\
\hline After & 3.96 & 0.32 & 3.76 & 3.99 & 4.19 & 0.43 & \\
\hline \multicolumn{8}{|c|}{ Platelet-lymphocyte ratio } \\
\hline Before & 134.11 & 58.98 & 91.98 & 122.46 & 160.87 & 68.89 & \multirow[t]{2}{*}{0.076} \\
\hline After & 132.41 & 54.40 & 94.42 & 121.17 & 158.00 & 63.58 & \\
\hline \multicolumn{8}{|c|}{ hsCRP, ${ }^{* * *} \mathrm{mg} / \mathrm{dL}$} \\
\hline Before & 1.45 & 2.65 & 0.26 & 0.58 & 1.18 & 0.92 & \multirow[t]{2}{*}{0.122} \\
\hline After & 1.08 & 2.14 & 0.29 & 0.43 & 0.85 & 0.56 & \\
\hline \multicolumn{8}{|l|}{$\begin{array}{l}\text { Others } \\
\text { spKt/V }\end{array}$} \\
\hline Before & 1.70 & 0.37 & 1.47 & 1.67 & 1.89 & 0.42 & \multirow[t]{2}{*}{$<0.001$} \\
\hline After & 1.78 & 0.40 & 1.52 & 1.76 & 2.04 & 0.52 & \\
\hline Glycosylat & & & & & & & \\
\hline Before & 6.64 & 1.09 & 5.79 & 6.57 & 7.35 & 1.56 & 0.161 \\
\hline After & 6.82 & 1.18 & 5.91 & 6.60 & 7.40 & 1.49 & \\
\hline
\end{tabular}

$\mathrm{CKD}$, chronic kidney disease; spKt/V, single-pool clearance of urea $\times$ dialysis time/volume of distribution of urea; hsCRP, serum high-sensitivity C-reactive protein; IQR, interquartile range; TSAT, transferrin saturation; $\mathrm{SD}$, standard deviation, $\mathrm{P}_{25}, 25$ th percentile; $\mathrm{P}_{75}, 75$ th percentile. ${ }^{*}$ Wilcoxon signed-rank test. ${ }^{* *}$ Only for diabetic patients. ${ }^{* * *}$ Sixty-six measurements in 20 patients.

\section{Laboratory Parameters}

Clinical laboratory parameters during HF-HD and the 12 months after switching to HDx are shown in Table 2. Median hemoglobin levels did not change significantly, being $11.90 \mathrm{~g} / \mathrm{dL}$ (IQR 2.3) in the 12 months of HF-HD and $11.80 \mathrm{~g} / \mathrm{dL}$ (IQR 2.2) after switching ( $p=0.397$ ). Median erythropoietin resistance was reduced significantly on HDx 3.37 (IQR 7.28) compared with during HF-HD 4.16 (IQR 8.03), $p=0.016$. The median ferritin levels decreased and median TSAT\% increased during the 12 
Table 3. Clinical outcomes before and after switching to HDx

\begin{tabular}{|c|c|c|c|c|c|}
\hline Characteristic & Events & Rate & \multicolumn{2}{|c|}{$95 \% \mathrm{CI}$} & $p$ value \\
\hline \multicolumn{6}{|c|}{ Global hospitalization rate (events/patient-year) } \\
\hline Before & 61 & 0.77 & 0.60 & 0.98 & \multirow{2}{*}{0.698} \\
\hline After & 57 & 0.71 & 0.55 & 0.92 & \\
\hline \multicolumn{6}{|c|}{ Hospitalization rate for cardiovascular causes } \\
\hline Before & 17 & 0.21 & 0.13 & 0.34 & \multirow{2}{*}{0.589} \\
\hline After & 14 & 0.18 & 0.10 & 0.30 & \\
\hline \multicolumn{6}{|c|}{ Hospitalization rate for causes related with dialysis } \\
\hline Before & 17 & 0.21 & 0.12 & 0.34 & \multirow{2}{*}{0.356} \\
\hline After & 12 & 0.15 & 0.08 & 0.26 & \\
\hline \multicolumn{6}{|c|}{ Hospitalization rate for infectious causes per patient-year } \\
\hline Before & 8 & 0.10 & 0.04 & 0.20 & \multirow{2}{*}{0.653} \\
\hline After & 10 & 0.13 & 0.06 & 0.23 & \\
\hline \multicolumn{6}{|c|}{ Hospitalization rates for others causes per patient-year } \\
\hline Before & 19 & 0.24 & 0.14 & 0.37 & \multirow{2}{*}{0.764} \\
\hline After & 21 & 0.26 & 0.16 & 0.40 & \\
\hline \multicolumn{6}{|c|}{ Hospital days per patient-year } \\
\hline Before & 473 & 5.94 & 5.41 & 6.50 & \multirow{2}{*}{$<0.001$} \\
\hline After & 353 & 4.41 & 3.97 & 4.90 & \\
\hline \multicolumn{6}{|c|}{ 30-day readmission rates per patient-year } \\
\hline Before & 12 & 0.15 & 0.09 & 0.27 & \multirow{2}{*}{0.259} \\
\hline After & 7 & 0.09 & 0.04 & 0.18 & \\
\hline
\end{tabular}

$\mathrm{CI}$, confidence interval; rate is defined as events per personyear. Person-year is the sum of each person's individual time in the population by 1 year at risk to the event hospitalization; Events are defined as hospitalization events with a duration longer than $24 \mathrm{~h}$.

months of HDx compared with the 12 months of HF-HD, but not significantly ( $p=0.855$ and $p=0.454$, respectively).

Median phosphorous levels decreased significantly from $4.47 \mathrm{mg} / \mathrm{dL}$ (IQR 1.73) during HF-HD to $4.29 \mathrm{mg} /$ dL (IQR 1.87) with HDx $(p=0.004)$. Median calcium levels were $8.80 \mathrm{mg} / \mathrm{dL}$ (IQR 0.98) during HF-HD and 8.88 $\mathrm{mg} / \mathrm{dL}$ (IQR 1.00) during HDx $(p=0.188)$. Median parathyroid hormone levels were $314.95 \mathrm{pg} / \mathrm{mL}$ (IQR 453.5) during HF-HD and $318.10 \mathrm{pg} / \mathrm{mL}$ (IQR 414) during HDx $(p=0.003)$.

The median levels of the studied markers of inflammation did not change significantly. The median albumin level was $4.01 \mathrm{~g} / \mathrm{dL}$ (IQR 0.43) during HF-HD and $3.99 \mathrm{~g} /$ $\mathrm{dL}$ (IQR 0.43) during HDx $(p=0.082)$. The median platelet-lymphocyte ratio was 122.46 (IQR 68.89) during HF$\mathrm{HD}$ and 121.17 (IQR 63.58) during HDx ( $p=0.076$ ). High-sensitivity CRP decreased from a median level of $0.58 \mathrm{mg} / \mathrm{dL}$ (IQR 0.92) during HF-HD to $0.43 \mathrm{mg} / \mathrm{dL}$ (IQR 0.56) during $\mathrm{HDx}(p=0.122)$. The median dialysis dose (spKt/V) was 1.67 (IQR 0.42) with HF-HD and 1.76 (IQR 0.52) with HDx $(p \leq 0.001)$. Median glycosylated hemoglobin levels were unchanged, being 6.57\% (IQR $1.56)$ and $6.60 \%$ (IQR 1.49) during HF-HD and HDx, respectively $(p=0.161)$.

\section{Hospitalization Rates}

Total patient-years at risk of hospitalization were 79.7 during the year of HF-HD and 80.0 in the 12 months after switching to HDx. The rate of hospitalization events per patient-year decreased from 0.77 (95\% CI: 0.60-0.98; 61 events) during HF-HD to 0.71 (95\% CI: 0.55-0.92; 57 events) with HDx, $p=0.698$ (Table 3). The hospitalization rate per patient-year due to cardiovascular events or due to events related to dialysis both decreased with $\mathrm{HDx}$ compared with HF-HD, while the rate due to infections increased, none of these changes were significant (Table 3). The rate of hospital days per patient-year was 5.94 (95\% CI: 5.41-6.50) with HF-HD and significantly decreased to 4.41 (95\% CI: 3.97-4.90) with HDx ( $p<0.001)$. The 30-days readmission rate per patient-year was not significantly different, being 0.15 and 0.04 with HF-HD and HDx, respectively $(p=0.259)$.

\section{Medication Use}

After switching to HDx, the median dose of ESA (SC epoetin- $\alpha$ ) significantly decreased from $12,000.00$ (IQR $24,000.00$ ) to $10,000.00$ (IQR $12,000.00)$ IU/month ( $p=$ 0.036 ), Table 4. Likewise, the mean dose of IV iron was significantly reduced from 73.46 (SD 142.13) mg/month to 66.36 (SD 167.34) $\mathrm{mg} / \mathrm{month}$ during HF-HD and $\mathrm{HDx}$, respectively $(p=0.003)$. The median dose of calcium carbonate showed variability in the different measurements $(p<0.001)$, but without clinical importance, see Table 4 . Finally, the median dose of aluminum hydroxide was not significantly different between the 2 treatment periods $(p=0.461)$.

\section{Adverse Events}

We observed a reduction in adverse events related to hemodialysis procedures after switching to HDx, especially we did not find any adverse events related to the dialyzer membrane, see Table 5.

\section{Discussion}

The purpose of this study was to evaluate the potential benefits of HDx in a stable chronic HD cohort. We found that transferring patients from HF-HD to HDx resulted in a significant reduction in the number of days in hospital per year but no significant reductions in absolute hos- 
Table 4. Medication consumption before and after switching to HDx

\begin{tabular}{|c|c|c|c|c|c|c|c|}
\hline Characteristics & Mean & SD & $\mathrm{P}_{25}$ & Median & $\mathrm{P}_{75}$ & IQR & $p$ value* \\
\hline \multicolumn{8}{|c|}{ ESA (epoetin $\alpha$ ), IU/month } \\
\hline Before & $15,109.82$ & $15,564.73$ & 0.00 & $12,000.00$ & $24,000.00$ & $24,000.00$ & 0.036 \\
\hline After & $14,010.29$ & $15,864.38$ & 0.00 & $10,000.00$ & $22,000.00$ & $22,000.00$ & \\
\hline \multicolumn{8}{|c|}{ IV iron, $\mathrm{mg} / \mathrm{month}$} \\
\hline Before & 73.46 & 142.13 & 0.00 & 0.00 & 100.00 & 100.00 & $<0.001$ \\
\hline After & 66.36 & 167.34 & 0.00 & 0.00 & 100.00 & 100.00 & \\
\hline \multicolumn{8}{|c|}{ Calcium carbonate, $\mathrm{mg} / \mathrm{month}$} \\
\hline Before & 749.28 & $1,001.60$ & 0.00 & 600.00 & $1,200.00$ & $1,200.00$ & $<0.001$ \\
\hline After & 989.51 & 167.34 & 0.00 & 600.00 & $1,800.00$ & $1,800.00$ & \\
\hline \multicolumn{8}{|c|}{ Aluminum hydroxide, $\mathrm{mg} / \mathrm{month}$} \\
\hline Before & 410.33 & $1,056.54$ & 0.00 & 0.00 & 0.00 & 0.00 & 0.471 \\
\hline After & 319.17 & 788.36 & 0.00 & 0.00 & 0.00 & 0.00 & \\
\hline
\end{tabular}

ESA, erythropoiesis-stimulating agents; IU, international unit; IV, intravenous; IQR, interquartile range; SD, standard deviation; $\mathrm{P}_{25}, 25$ th percentile, $\mathrm{P}_{75}$, 75th percentile. ${ }^{*}$ Wilcoxon signed-rank test.

pitalization rates nor readmission rates. As anticipated, there was a significant reduction in erythropoietin use and erythropoietin resistance.

In the context of an expanding global population with kidney disease $[17,18]$ and the subsequent growth in the number of patients with ESKD, advances in dialysis technologies and patient care are paramount to improving patient outcomes and reduce the burden of ESKD on healthcare systems worldwide [19]. Expanded hemodialysis offers for the first time the ability to remove large middle molecules in chronic dialysis populations without the need for machine adaptation to enable convection [20]. A recent multicenter prospective study demonstrated a significant reduction in large middle molecules without a significant reduction in serum albumin over a 6-month treatment period with $\mathrm{HDx}$ [21]. This study by Krishnasamy et al. [21] was undertaken to address questions of efficacy for removal of the large molecules and the safety of potential albumin loss on a more porous membrane. With these efficacy and safety issues after addressed, further work is required to identify potential clinical benefit of HDx over conventional therapies such as HF-HD.

In designing this study, it was anticipated that potential patient benefit of HDx would come from reduced chronic inflammation, reduced secondary immune deficiency, reduced cardiac events, and reduced erythropoietin resistance. In this context, the data reported here on the impact of switching patients from HF-HD to HDx on laboratory parameters, hospitalization rates, and medication use in a cohort of patients in Colombia provide further insight
Table 5. Adverse events related to hemodialysis procedure

\begin{tabular}{lcl}
\hline $\begin{array}{l}\text { Adverse events related to hemodialysis } \\
\text { procedure }\end{array}$ & $\begin{array}{l}\text { Before } \\
\text { phase }\end{array}$ & $\begin{array}{l}\text { After } \\
\text { phase }\end{array}$ \\
\hline Clotted dialyzer & 4 & 1 \\
Hematoma & 3 & 0 \\
Hypotension & 1 & 1 \\
Infection of vascular access & 5 & 3 \\
Insufficient weight loss $>$ or $<1 \mathrm{~kg}$ & 2 & 0 \\
Reaction type A & 1 & 0 \\
Bleeding $>150 \mathrm{~mL}$ & 2 & 0 \\
\hline Total & 18 & 5 \\
\hline
\end{tabular}

into the potential benefits of HDx. Over the 24 months of the study, a number of positive outcomes associated with the switch to HDx were observed. During the 12 months of HDx, there was a significant reduction in the rate of hospital days per patient-year as well as a trend toward a reduction in the hospitalization rate compared with the 12 months of HF-HD therapy. However, there was no observed reduction in infection-related events.

During the 12 months of HDx, the doses of ESA and IV iron were both reduced compared with the previous 12 months of HF-HD therapy, while hemoglobin levels remained stable, resulting in a net improvement in erythropoietin resistance. There are a number of mechanisms by which HDx could have improved the erythropoietin resistance including improved clearance of hepcidin, a middle molecule which contributes to increased degrada- 
tion of ferroportin and subsequent iron deficiency [22]. It has also been reported that increased levels of inflammatory mediators have also been linked with anemia [23], and we observed a nonsignificant decrease in markers of inflammation to support this hypothesis. Interestingly, this study population had relatively low levels of inflammation seen as measured by hsCRP, in comparison to other reports [24]. Furthermore, our findings coincide with a recent randomized clinical trial that showed that compared to HD performed with high-flux dialyzers, HDx was associated with a superior removal of inflammatory cytokines, improving iron metabolism in a manner independent of that related to hepcidin [25].

Other interesting trends were observed during the study. First, the single-pool Kt/V was improved during the 12 months of HDx compared with the 12 months of HF-HD therapy. This may be indicative of improved clearance properties with HDx. In addition to the improved dialysis dose, the level of albumin was unchanged after switching to $\mathrm{HDx}$, suggesting that despite the improved removal properties of the membrane, the removal of albumin should not be greater than with high-flux HD or other modalities. Although not significant, we observed an interesting trend toward a reduction in the level of hsCRP after switching to HDx. Intriguingly, we observed a nonsignificant trend toward a reduction in the rate of hospitalizations related to cardiovascular events with HDx; this aligns with observations from the general population which have shown that a raised hsCRP is associated with cardiac events [26]. While a protective effect of HDx on the heart remains to be proven, it will be interesting to observe if these important trends are replicated in larger controlled studies.

Our study does have some limitations. Most importantly that although this was a multicenter study, when the study was complete, only 81 patients met full study criteria for analysis. While a study population of this size enables the observation of changes in parameters, many of these did not achieve statistically significance because of the population size. Second, a "before and after" design introduces the potential for bias that is secondary to the changes in dialysis care after switching from high-flux HD to HDx. Finally, this was a single-arm observational study. Further work now needs to occur in larger cohorts with control arms to confirm the results observed in this study and explore other potential benefits in multiyear studies. Also, it would be interesting to observe long-term effects on symptoms in patients with chronic hemodialysis such as carpal tunnel syndrome, pruritus, postdialysis asthenia, and restless legs syndrome.
Given the scarcity of outcome data for HDx, this realworld evidence in a substantial number of patients provides the HD community with further insight into the utility of HDx. We followed patients for 24 months, and the reduced medication consumption and rate of hospital days per patient that we observed in the 12 months of HDx represent encouraging improvements in the quality of care received by dialysis patients. Furthermore, they have the potential to help inform wider clinical decisions regarding choice of dialysis treatment modality and may help to reduce the impact of ESKD on patients and healthcare systems.

\section{Conclusion}

In this cohort of chronic HD patients, switching to HDx was associated with improvements in the rate of hospital days per patient-year and medications use, including ESA and IV iron. These observations may have important implications for patients and healthcare systems.

\section{Acknowledgements}

The authors wish to express their gratitude to all the patients and nursing teams who participated in the study. The authors thank all the investigators who participated in the Colombian Registry of Expanded Hemodialysis study: Maria P. Dazzarola, MD (Cali), Edward A. Martinez, MD (Bucaramanga), and Sylvia C. Quiñonez, MD (Bogota).

\section{Statement of Ethics}

As this was an observational study, where the procedure of HD therapy was not changed in any respect, the study was considered without risk. All patients provided written informed consent, and the study was conducted in accordance with the principles of the Helsinki Declaration and Good Clinical Practices. The study protocol was approved by the clinical research ethics committee of Renal Therapy Services (RTS), December 11, 2018, Minute, Item No. 025 .

\section{Conflict of Interest Statement}

R.S. and J.A. are employed by Baxter Latin America, Bogotá, D.C., Colombia; J.V. and A.S. are employed by Renal Therapy Services (RTS), Bogotá, Colombia; R.S. has received grant/research support from RTS, Colombia, and served as a statistical consultant for this study. C.H. is from the Department of Medicine, Hawke's Bay District Health Board, Hastings, New Zealand. 


\section{Funding Sources}

This study was supported by Renal Therapy Services, Colombia, an independent entity owned by Baxter International, Inc. Renal Therapy Services contributed to study design and data collection, analysis, and interpretation and reviewed the manuscript for scientific accuracy. Editorial support for the development of this manuscript was provided by Daniel Johnson, PhD, Apurva Davé, $\mathrm{PhD}$, and Nicholas Schumacker, PhD, SciMentum (Nucleus Global), with funding provided by Baxter Healthcare Corporation, Deerfield, IL, USA.

\section{Author Contributions}

Mr. Sanabria, Ms. Vesga, Mr. Sanchez, and Ms. Suarez: original research project conception and design, data acquisition, and data interpretation. Mr. Hutchison and Mr. Ariza: original research project conception and design and data interpretation. All authors contributed to the research conception, protocol design, and analysis and interpretation of the data. All authors contributed to the development and critical review of the manuscript and provided final approval for publication. All authors agree to be accountable for all aspects of the work in ensuring that questions related to the accuracy or integrity of any part of the work are appropriately investigated and resolved.

\section{References}

1 Mills KT, Xu Y, Zhang W, Bundy JD, Chen CS, Kelly TN, et al. A systematic analysis of worldwide population-based data on the global burden of chronic kidney disease in 2010. Kidney Int. 2015;88(5):950-7.

2 Bello AK, Levin A, Lunney M, Osman MA, Ye F, Ashuntantang GE, et al. Status of care for end stage kidney disease in countries and regions worldwide: international cross sectional survey. BMJ. 2019;367:15873.

3 United States Renal Data System [Internet]. USRDS Annual Data Report, Volume 2, Chapter 5: Mortality, 2018 [cited 2019 Dec 16]. Available from: https://www.usrds. org/2018/view/v2_05.aspx.

4 Hazara AM, Bhandari S. Early mortality rates after commencement of maintenance hemodialysis: a systematic review and meta-analysis. Ther Apher Dial. 2019.

5 Naylor KL, Kim SJ, McArthur E, Garg AX, McCallum MK, Knoll GA. Mortality in incident maintenance dialysis patients versus incident solid organ cancer patients: a population-based cohort. Am J Kidney Dis. 2019; 73(6):765-76.

6 United States Renal Data System [Internet]. USRDS Annual Data Report, Volume 2, Chapter 4: Hospitalizations, Readmissions, Emergency Department Visits, and Observation Stays, 2018 [cited 2019 Dec 16]. Available from: https: //www.usrds.org/2018/view/ v2_04.aspx.

7 Luyckx VA, Tonelli M, Stanifer JW. The global burden of kidney disease and the sustainable development goals. Bull World Health Organ. 2018;96(6):414-22D.

8 Wolley MJ, Hutchison CA. Large uremic toxins: an unsolved problem in end-stage kidney disease. Nephrol Dial Transplant. 2018; 33(Suppl_3):iii6-iii11.

9 Dai L, Golembiewska E, Lindholm B, Stenvinkel P. End-stage renal disease, inflammation and cardiovascular outcomes. Contrib Nephrol. 2017;191:32-43.

10 Nowak KL, Chonchol M. Does inflammation affect outcomes in dialysis patients? Semin Dial. 2018;31(4):388-97.

11 Young B, Zaritsky J. Hepcidin for clinicians. Clin J Am Soc Nephrol. 2009;4(8):1384-7.

12 Ronco C, Marchionna N, Brendolan A, Neri M, Lorenzin A, Martínez Rueda AJ. Expanded haemodialysis: from operational mechanism to clinical results. Nephrol Dial Transplant. 2018;33(Suppl_3):iii41-7.

13 Kirsch AH, Lyko R, Nilsson LG, Beck W, Amdahl M, Lechner P, et al. Performance of hemodialysis with novel medium cut-off dialyzers. Nephrol Dial Transplant. 2017;32(1):165-72.

14 Teatini U, Liebchen A, Nilsson LG, Beck W, Longhena GR. Effect of a more permeable dialysis membrane on ESA resistance in hemodialysis patients: a pilot investigation. Blood Purif. 2016;41(1-3):80-6.

15 Florens N, Juillard L. Expanded haemodialysis: news from the field. Nephrol Dial Transplant. 2018;33(Suppl_3):iii48-52.

16 Fischbach M, Wühl E, Reigner SCM, Morgan Z, Schaefer F. Efficacy and long-term safety of C.E.R.A. maintenance in pediatric hemodialysis patients with anemia of CKD. Clin J Am Soc Nephrol. 2018;13(1):81-90.

$17 \mathrm{Ng} \mathrm{JK}, \mathrm{Li}$ PK. Chronic kidney disease epidemic: how do we deal with it? Nephrology. 2018; 23(Suppl 4):116-20.

18 ERA-EDTA [Internet]. The hidden epidemic: worldwide, over 850 million people suffer from kidney diseases, 2018 [cited 2019 Dec 16]. Available from: http://www.era-edta.org/ press/180626_Prevalence_Data_Project.pdf.

19 Wetmore JB, Collins AJ. Global challenges posed by the growth of end-stage renal disease. Ren Replace Ther. 2016;2(1):15.

20 Hutchison CA, Wolley M. The rationale of expanded hemodialysis therapy (HDx). Contrib Nephrol. 2017;191:142-52.

21 Krishnasamy R, Hawley CM, Jardine MJ, Roberts MA, Cho Y, Wong M, et al. A trial evaluating mid cut-off value membrane clearance of albumin and light chain in hemoDialysis patients: a safety device study. Blood Purif. 2020;49:468-78.

22 Ganz T, Nemeth E. Iron balance and the role of hepcidin in chronic kidney disease. Semin Nephrol. 2016;36(2):87-93.

23 Zivot A, Lipton JM, Narla A, Blanc L. Erythropoiesis: insights into pathophysiology and treatments in 2017. Mol Med. 2018;24(1):11.

24 den Hoedt CH, Bots ML, Grooteman MPC, van der Weerd NC, Mazairac AHA, Penne $\mathrm{EL}$, et al. Online hemodiafiltration reduces systemic inflammation compared to low-flux hemodialysis. Kidney Int. 2014;86:423-32.

25 Lim JH, Jeon Y, Yook JM, Choi SY, Jung HY, Choi JY, et al. Medium cut-off dialyzer improves erythropoiesis stimulating agent resistance in a hepcidin-independent manner in maintenance hemodialysis patients: results from a randomized controlled trial. Sci Rep. 2020;10(1):16062.

26 Carrero JJ, Andersson Franko M, Obergfell A, Gabrielsen A, Jernberg T. hsCRP level and the risk of death or recurrent cardiovascular events in patients with myocardial infarction: a healthcare-based study. J Am Heart Assoc. 2019;8(11):e012638.
Hospitalization and Medication

Consumption Using HDx
Nephron 2021;145:179-187

DOI: $10.1159 / 000513328$ 